\title{
An Improved Procedure for Synthesis of DL-4-Hydroxy-3-methoxymandelic Acid (DL-“Vanillyl"-mandelic Acid, VMA)
}

\author{
Alexander J. Fatiadi and Robert Schaffer \\ Institute for Materials Research, National Bureau of Standards, Washington, D.C. 20234
}

(January 23, 1974)

\begin{abstract}
An improved procedure for synthesis of DL-4-Hydroxy-3-methoxymandelic Acid (DL-Vanillylmandelic Acid, VMA) entails slow addition of an ice-cold, aqueous solution of glyoxylic acid to an icecold alkaline solution of guaiacol, with efficient mechanical stirring. This one-step condensation procedure provides VMA in 68-75 percent yield.
\end{abstract}

Key words: Alkaline condensation; glyoxylic acid; quaiocol; synthesis; vanillyl-mandelic acid; VMA.

\section{Introduction}

In connection with a program on clinical standards being conducted at the National Bureau of Standards, there was need for a simple, practical method for the large-scale preparation of pure DL-4-hydroxy-3methoxymandelic acid (IV) in high yield. The Denantiomorph of IV is one of the major metabolites of epinephrine and norepinephrine found in normal human urine $[1],{ }^{1}$ but abnormally high concentrations of IV are found in the urine of patients having pheochromocytoma [2].

A literature survey revealed that IV has been prepared in low (19\%) to moderate $(45 \%)$ yield by a multiplestep procedure from vanillin via the cyanohydrin intermediate [3-5]. An alternative route for the synthesis is the procedure of Goodman and co-workers [6], who made use of a reaction, previously employed in a synthesis of vanillin [7], in which guaiacol (I) was added to glyoxylic acid (II), and without isolation the intermediate product (III) was directly oxidized via IV to vanillin.
The authors [6] demonstrated that IV was, indeed, produced in this reaction by showing that mixing $(68 \mathrm{~h}$ at $\left.25^{\circ}\right)$ of I $(1.14 \mathrm{~mol})$ with II $(1.35 \mathrm{~mol})$ in basic media gave IV in 28 percent yield. Because of its simplicity, this one-step process for the synthesis of IV was examined to seek improvement in its yield.

Our procedure for preparation of IV (developed for use with two moles of the reagents) utilizes slow addition of an ice-cold, aqueous solution of II to a cold alkaline solution of I, with efficient mechanical stirring. By this procedure, the intermolecular reaction between glyoxylate ions that promotes a competitive Cannizzaro reaction of II (a kinetically controlled process) is lessened, permitting normal addition to II (or its ion) of the phenoxide ion from I (para position activated due to resonance) by a thermodynamically controlled process, and this contributes to an increase in the yield of IV. The normal reaction between I and II to yield III is rather fast considering the low temperature at which it is conducted. Reaction of I with II for $5 \mathrm{~h}(4 \mathrm{~h}$ for addition of II at -5 to $0^{\circ}$ and $1 \mathrm{~h}$ for additional stirring at $0-15^{\circ}$ ) gave IV in 40 percent yield, and condensation

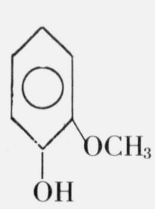

I

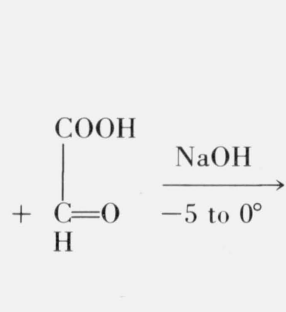

II

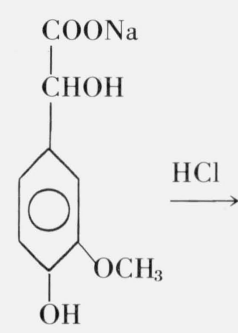

III

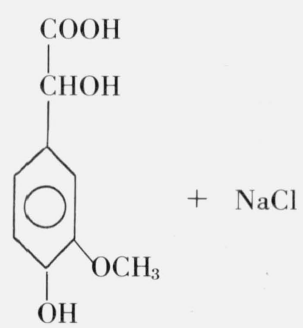

IV

${ }^{1}$ Figures in brackets indicate the literature references at the end of this paper. 
for $7 \mathrm{~h}\left(3 \mathrm{~h}\right.$ of stirring at $\left.0-15^{\circ}\right)$ after introduction of II, gave IV in 45 percent yield. Recovered unreacted I at this stage was 0.76 mol.

The importance of slow introduction of $\mathrm{I}$ is evident from the fact that, when the reaction was performed at $25^{\circ}$ (total stirring for $24 \mathrm{~h}$ ), the yield of IV was 54 percent (nearly twice that previously reported), but raising the reaction temperature to $35-40^{\circ}$ or $50^{\circ}$ reduced the yield of IV to 42 and 32 percent, respectively. The condensation provided a maximum yield of IV after $18 \mathrm{~h}$, and the product was usually recovered after $24 \mathrm{~h}$ to give IV in an overall yield of 65 percent. A longer time $(8 \mathrm{~h})$ for introduction of II and $16 \mathrm{~h}$ for stirring or longer condensation time $(120 \mathrm{~h})$ did not improve the yield further. Replacement of sodium carbonate by sodium hydroxide did not improve the yield of IV. However, conducting the condensation in dilute solution was found advantageous; for example, on increasing the volume used by 50 percent and 100 percent, the yield of IV was increased by 10 and 15 percent, respectively. In view of the large volume of solution that would have had to have been processed, this was not practical as a laboratory procedure. Salting out before extraction improved the yield of IV considerably.

\section{Experimental Procedure}

Thin layer chromatography (T.L.C.) was performed either on nonactivated silica gel $\mathrm{G}$ plates with $4: 4: 1$ $(\mathrm{v} / \mathrm{v})$ chloroform-acetic acid-water followed by spraying with $3 M$ sulfuric acid in methanol and heating for $2 \mathrm{~min}$ in an oven at $110{ }^{\circ} \mathrm{C}$ or on silica gel $\mathrm{GF}$ plates (254-nm irradiation).

DL-4-Hydroxy-3-methoxymandelic Acid-A solution of $176 \mathrm{~g}(4.4 \mathrm{~mol})$ of sodium hydroxide in $100 \mathrm{ml}$ of water (precooled to $15^{\circ}$ ) was combined with $1 \mathrm{~kg}$ of crushed ice, and to this mixture, surrounded by an ice-salt bath, was added with efficient stirring, $250 \mathrm{~g}$ $(2.014 \mathrm{~mol}$ ) of guaiacol (I) (solution temperature, $\left.-7^{\circ}\right)$. While stirring, an ice-cold solution of $225 \mathrm{~g}$ $(2.5 \mathrm{~mol})$ of glyoxylic acid monohydrate (II) in $400 \mathrm{ml}$ of water was introduced dropwise during $4 \mathrm{~h}$, the reaction temperature being kept at 0 to $-5^{\circ}$. If II is added too fast, an undesirable white precipitate appears at the end of the addition period, but this dissolves on further stirring. The solution was stirred for an additional $20 \mathrm{~h}$ (total $24 \mathrm{~h}$ ) while the temperature slowly rose to $\sim 20^{\circ}$. The dark-brown solution was acidified with $375 \mathrm{ml}$ of concentrated hydrochloric acid, saturated with salt $(700 \mathrm{~g})$, and extracted with benzene $(3 \times 100 \mathrm{ml})$. After drying the benzene extract (sodium sulfate), concentration to a syrup gave unreacted I $(10 \mathrm{~g})$. The aqueous layer was next extracted with ethyl acetate $(15 \times 250 \mathrm{ml})$; the next extract $(250 \mathrm{ml})$ usually gives less than $1.2 \mathrm{~g}$ of IV on evaporation. The extracts were combined, dried $\left(\mathrm{Na}_{2} \mathrm{SO}_{4}\right)$, treated with acid-washed charcoal $(3 \mathrm{~g})$, and carefully concentrated to a syrup in a rotary evaporator. The pink syrup was cooled, and the product crystallized. This was filtered and washed with cold ethyl acetate to give almost colorless crystals of IV $260 \mathrm{~g},(65 \%)$ in several crops; $\mathrm{mp} 128-130^{\circ}$. Crude IV can be recrystallized from $1: 2(\mathrm{v} / \mathrm{v})$ ethyl acetatecyclohexane, $1: 3(\mathrm{v} / \mathrm{v})$ 2-butanone-cyclohexane, $1: 3$ $(\mathrm{v} / \mathrm{v})$ ether-benzene, or acetonitrile. The analytical sample was recrystallized from ethyl acetate (charcoal and concentration) and then from 1:3 (v/v) 2-butanonecyclohexane (with stirring at room temperature to prevent formation of clusters); colorless crystals; mp $132-133^{\circ}$ (dried in vacuo over concentrated sulfuric acid); lit mp $133^{\circ}$ (ref. [3]), 131-133 (refs. [4] and [5]) $134-135^{\circ}$ (ref. [6]); $\nu_{\max }^{\mathrm{KBr}} 1870,1748$, and $1745 \mathrm{~cm}^{-1}$ $(\mathrm{C}=\mathrm{O}$ stretch $)$; n.m.r. (methyl sulfoxide- $\left.d_{6}\right)$ : singlet at $83.70\left(-\mathrm{OCH}_{3}\right)$, at $\delta 4.95(-\mathrm{C}-\mathrm{H})$, multiplet at $\delta 6.8$ (aromatic protons), broad peak at $\delta 8.65$ (changed on treatment with a drop of pyridine- $d_{5}$ to a sharp singlet at 88.73 ). T.L.C.; $R_{F} 0.63 ; \lambda_{\max }$ of IV in $M$ $\left.\mathrm{K}_{2} \mathrm{CO}_{3}\right)$ was at $251 \mathrm{~nm}\left(\epsilon_{n M} 1.022\right)$ and $293 \mathrm{~nm}(0.429)$. Samples of IV were titrated with standardized sodium hydroxide using a $\mathrm{pH}$ meter to the first inflection point of the titration curve; $p K_{1} 3.75$ (carboxyl group) and $p K_{2} 9.80$ (phenolic group). The sample contained a carboxylic acid equivalent of 99.83 percent.

The authors are most pleased to acknowledge the partial support of this work by the National Institute of General Medical Sciences (NIH); the authors also thank J. K. Taylor, R. A. Durst, and E. R. Deardorff of this Division for titration measurements.

\section{References}

[1] Shaw, K. N. F., McMillan, A., and Armstrong, M. D., Fed. Proc. 15, 353 (1956); J. Biol. Chem., 226, 255 (1957).

[2] Armstrong, M. D., McMilland, A., and Shaw, K. N. F., Biochim. Biophys. Acta 25, 422 (1957).

[3] Gardner, J. A. F., and Hibbert, H., J. Amer. Chem. Soc. 66, 607 (1944)

[4] Shaw, K. N. F., McMillan, A., and Armstrong, M. D., J. Org. Chem. 23, 27 (1958).

[5] Recondo, E. F., and Rinderknecht, H., J. Org. Chem. 25, 2248 (1960).

[6] Goodman I., Olenczak, A. P., Scherrer, J. W., and Hiatt, R. B., Biochim. Biophys. Acta 156, 364 (1968).

[7] Boedecker, F., and Volk, H., U. S. Patent 2,062,205; J. Kamlet, U. S. Patent 2,640,083 [Chem. Abstr. 48, 5884 (1954)].

(Paper 78A3-821) 